\title{
2006-223: SOLID MODELING AS THE CORNERSTONE OF AN INTRODUCTION TO ENGINEERING COURSE
}

\section{William Howard, East Carolina University}

William E.(Ed) Howard is an Assistant Professor of Engineering at East Carolina University. Prior to joining ECU, he was a faculty member and program coordinator at Milwaukee School of Engineering. Howard has fourteen years of industrial experience in design and project engineering functions. He received BS and MS degrees from Virginia Tech, and his $\mathrm{PhD}$ from Marquette University. Howard is a registered Professional Engineer in Wisconsin.

\section{Joseph Musto, Milwaukee School of Engineering}

Joe Musto is an Associate Professor and Mechanical Engineering Program Director at Milwaukee School of Engineering. He holds a B.S. from Clarkson University (Potsdam, NY), and an M.Eng. and Ph.D. from Rensselaer Polytechnic Institute (Troy, NY), all in Mechanical Engineering. His industrial experience includes engineering positions with Eastman Kodak Company (Rochester, NY) and Brady Corporation (Milwaukee, WI). He is a registered Professional Engineer in the state of Wisconsin. 


\title{
Solid Modeling as the Cornerstone of an Introduction to Engineering Course
}

\begin{abstract}
Most engineering programs have freshman-level courses that are designed to introduce students to the engineering profession, teach problem-solving and design skills, and motivate the students. Engineering graphics is a subject that is also usually taught at the freshman level, sometimes integrated with the introduction to engineering course, other times as a stand-alone course. Solid modeling software has become widely used in education over the past decade, primarily in existing engineering graphics courses. Because solid modeling is an integral part of the product design cycle, it can be used as a gateway to explore engineering design and to relate coursework to real world applications. The use of solid modeling software at the freshman level also has the potential for improving the confidence level of some students regarding their abilities to perform engineering work. A proposed course structure centered around solid modeling is presented, and examples of partial implementations are given.
\end{abstract}

\section{Background}

Most engineering curricula have some sort of an Introduction to Engineering course for freshman students. Brannon and Wankot ${ }^{1}$ found that more than two-thirds of engineering programs contain such an introductory course. The content of such courses varies widely from program to program. At some institutions which have a common first year for all engineering freshmen, the course is designed to include an introduction to the various engineering disciplines. This introduction is intended to assist students in making a choice of majors after the freshman year. Many freshman classes are intended to develop specific student skills in areas such graphics and computer programming. Requirements from the Accreditation Board for Engineering and Technology $(\mathrm{ABET})^{2}$ have resulted in the inclusion of topics such as teamwork, ethics, and the engineering profession at the freshman level.

Design is also a component of many first-year engineering courses. The inclusion of design at this level is probably one of the most-discussed topics in engineering education. A common argument against design content at the freshman level is that without the mathematical and analytical skills, student design projects tend to trivialize the detailed design steps. Crockett et $\mathrm{al}^{3}$ counter this argument by pointing out that throughout the history of engineering, tools are often used before they are fully understood; that is, innovations often lead to better theoretical understanding rather than vice versa.

Whatever the course content, a common goal of almost all freshman engineering courses is to motivate the students. Often, engineering faculty interpret this goal as a need for design-build experiences, since the stereotypical engineering student likes "hands-on" activities. However, these freshman design/build projects can have the effect of rewarding students who come into college with good hands-on skills and discouraging other students. Dee and Livesay ${ }^{4}$ surveyed students who left engineering and asked them to select the type of courses they would most like to take. Courses with hands-on experiments and laboratories were the least favored by these students. Besterfield-Sacre et $\mathrm{al}^{5}$ found that students who left engineering in good academic 
standing had lower confidence in their "engineering skills" than those who were retained. While developing hands-on skills may be an important goal of a first-year course, faculty members should bear in mind that many students are intimidated by hands-on projects.

Engineering Graphics, Solid Modeling, and Design

Engineering graphics is a subject that is normally taught in the freshman year, either as a part of an introduction to engineering course or as a separate course or course sequence. The addition of 3-D solid modeling software has occurred in many of these courses without fundamentally changing the course itself. That is, solid modeling software has simply replaced or supplemented 2-D CAD software, just as in previous years 2-D CAD replaced or supplemented hand drawing. However, the introduction of solid modeling in industry has resulted in profound changes in how products are designed. While CAD was used mostly for design documentation in the past, solid modeling is an integral part of the design process, especially in mechanical design. The solid model is the data source for analysis, rapid prototyping, manufacturing, mold design, and for the 2-D drawings needed for documentation. Solid modeling software, along with the advances in computer hardware of the past fifteen years, has enabled the design cycle to be compressed in many industries.

One topic of debate among engineering educators is whether or not 2-D graphics should be taught before 3-D. A consideration that is sometimes lost in this debate is the meaning of the term 2-D graphics. This term can be used to describe:

1. The representation of 3-D objects with 2-D multi-view engineering drawings, and

2. The representation of objects/systems that are idealized as two-dimensional, such as floor plans, site plans, and circuit diagrams.

If engineering graphics instruction is to include 2-D graphics as described by the first definition, then $3 \mathrm{D}$ objects must be introduced at the beginning of the course. Even if the course uses only hand drawing techniques, the relationship between 3-D objects and 2-D drawing views must be understood.

This understanding of the relationship between 3-D objects and their 2-D representations (visualization) is particularly important when considering the retention of women students. Many studies have shown that on tests to measure visualization ability, female freshman engineering students score lower than do male freshman engineering students. Sorby and Bartsmann $^{6}$ found that the results of this test are a good predictor of success in a first engineering graphics course. Peters et $\mathrm{al}^{7}$ also found that success in a first graphics course was related to visualization ability as measured by a standard test, but that academic success in other courses was not related to visualization ability. At Michigan Technological University, Sorby ${ }^{8}$ reports that a class to develop and improve students' visualization abilities has been developed and improved, with positive results in engineering graphics grades and retention rates.

The studies referenced above correlate with the anecdotal experience of the authors: we have known several female engineering students who were successful in their studies, but recall their freshman engineering graphics classes as among the biggest challenges they faced in completing their program of study. As noted earlier, students who leave engineering in good academic standing have lower confidence in their "engineering skills." At the freshman level, students 
may consider success in a graphics class to be a good indicator of their ability to do engineering work, since it is usually their first class devoted to an engineering topic.

Based on these considerations, it can be argued that engineering graphics is not a subject that should be taught to first-semester freshmen at all. However, this remedy would be impractical for many programs. Since graphics does not require calculus, physics, or chemistry prerequisites, it is usually one of the few engineering courses that can be placed early in the curriculum. If an engineering graphics course is to be taught at the freshman level, then improving the visualization skills of students should be a course goal.

Many solid modeling software packages contain tools that are especially useful for developing visualization skills. For example, the SolidWorks ${ }^{\circledR} 2006$ solid modeling software ${ }^{9}$ allows the display of a part in a multi-view window, as shown in Figure 1. Three standard views are shown along with an isometric view, allowing the relationship between views to be better understood. In Figure 1, note that highlighting a particular face in the isometric view causes that face to be highlighted in the standard views. Another feature of the SolidWorks software is the inclusion of eDrawings $^{\mathrm{TM}}$, a tool that allows the animation of 2-D drawings ${ }^{10}$. The eDrawings viewer allows the views of a 2-D drawing to be rotated, so that the relation of that view to the 3-D object can be explored.

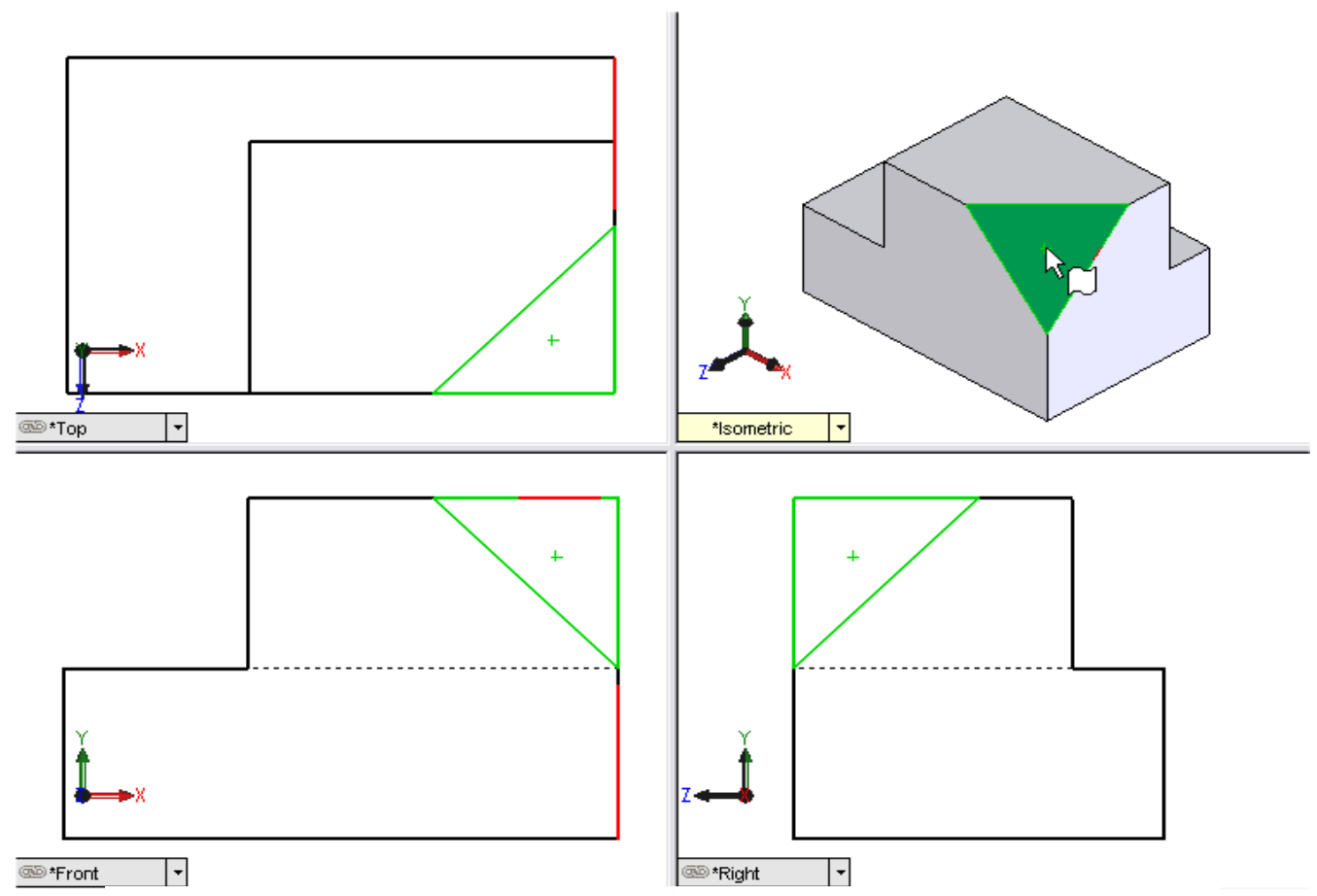

Figure 1

Multi-View Window in SolidWorks® 2006

The authors believe that solid modeling software can be used to effect major changes in not only the teaching of engineering graphics, but in the freshman experience as a whole. The role of solid modeling as an integral part of the engineering design process can be the basis of an introduction to the design process. Case studies are especially helpful here, as they allow students to relate their class work to real-world experiences. Also by reviewing case studies, 
students can see that engineering design process is not the step-by-step procedure outlined in many textbooks. In their excellent book Product Design: Techniques in Reverse Engineering and New Product Development, Otto and Wood ${ }^{11}$ detail six examples of product development processes that differ widely, but make sense for the particular company/product discussed.

One of the most attractive features of modern solid modeling software is the ease of use. The authors have taught solid modeling basics to hundreds of high school students ${ }^{12,13}$ and to engineering students of all levels. Students can quickly become proficient with solid modeling software, allowing students to begin design projects within a few weeks of first exposure. And while previous experience with CAD software is certainly helpful, most students are capable of achieving a level of performance that will allow them to produce design projects that they are proud of. At the same time, a common reaction is that the software is fun to use. While having fun in class may not be a course objective, motivating and retaining students are certainly important goals for most freshman courses.

Proposed Outcomes for an Introduction to Engineering Course

Based on the discussion above, a set of course outcomes that would apply to most first-semester freshman introduction to engineering course is:

Upon completion of this course, the student will be able to:

- Solve simple engineering problems in a structured format.

- Identify steps of the engineering design process.

- Identify skills necessary to be a member of a project team.

- Model parts and assemblies with CAD software.

- Understand the relationships between 3-D objects and their 2-D representations.

- Create and dimension 2-D drawings of 3-D objects.

- Communicate the results of a design project via written report and oral presentation.

These can be considered a "core" set of outcomes for the course. Many other outcomes could be added relative to program objectives and outcomes, including those relating to:

- Knowledge of current events.

- Awareness of the engineering disciplines.

- Skills in software other than CAD.

- Knowledge of the engineering profession.

- Familiarity with ethical issues in engineering.

- Awareness of project management methods and tools.

While addressing the chosen outcomes, it is important to keep in mind the broader goals of motivating and retaining the students.

Proposed Course Structure

The content of a 15-week semester-long introduction to engineering course that is centered around solid modeling is presented here. We have assumed two lecture hours per week and one lab period per week. 
Lecture Topics

Intro to Engineering Graphics (2 sessions)

Pictorial Projections (3)

Multi-View Projections (2)

Auxiliary and Section Views (2)

Assembly Drawings (2)

Dimensions and Tolerances (4)

Engineering Problem Solving (3)

The Engineering Design Process (2)

Engineering Teams (3)

Project Management (3)

Project Reporting (4)
Laboratory Topics

Intro to CAD software (1 session)

Visualization Exercises - Parts (2)

Visualization Exercises - Drawings (2)

Part Modeling (2)

Assembly Modeling (2)

Drawings (2)

Assembly Drawings (1)

Project Work (3)

The topics listed are not necessarily in the order they would be covered; it may be beneficial to mix the graphics topics and the project-related topics throughout the semester.

The project may be a "virtual" project only, with a CAD model as the final product, or a designbuild project. In either case, a project provides the platform for introducing the teamwork, project management, and communications topics that will be important throughout an engineering curriculum. Summers et $\mathrm{al}^{14}$ point out that projects have been added to many courses within a typical program, and to maximize their educational benefit, project management skills should be taught and applied, regardless of the scope of the project.

Students like to see how the skills they are learning are used in the real world. One of the most effective means of relating solid modeling to real world projects is through the use of invited speakers. Speakers who are able to discuss the engineering design process at their companies are especially relevant. Local CAD resellers are often a good source for locating speakers. A second method is to find articles in popular and trade publications mentioning solid modeling. Often companies will release stories about how they reduced development time for a new product by using solid modeling, rapid prototyping, finite element analysis, and other modern design tools. Similar case studies are found on CAD vendor websites. However it is accomplished, students like to see that the tool they are learning to use is relevant to their career.

\section{Examples}

A course utilizing many of the concepts presented here has been implemented at Milwaukee School of Engineering. This course, ME-160, Introduction to Mechanical Engineering and Design, is a three-credit course required for first-quarter freshmen mechanical engineering students. During a two-hour lab session each week, hand sketching and solid modeling are taught. One lecture hour per week is devoted to problem solving and the design process, and the other lecture hour is used primarily for invited speakers. The speakers have been selected to represent a wide variety of engineering careers, and include senior managers as well as younger engineers who are a year or two into their careers. The course culminates in a creative design project, in which teams of students formulate a design and present it orally. Because of the time constraint of a ten-week quarter, this "paper design" format is more practical than a design-build exercise. The project varies from instructor to instructor; some prefer to have all students work 
on the same project, while others allow the students to select their own project. Popular assignments have been those related to college life: entertainment centers or bed lofts for dorm rooms and a student "multi-tool" are examples.

At East Carolina University, first-semester freshman students are required to take a six-credit course that integrates graphics, professional practice, and introductions to mechanical and electrical engineering. The course also includes a design-build project utilizing robot kits from GEARS Educational Systems, LLC ${ }^{15}$. Many elements of the proposed course structure outlined in this paper have been used in this course. The semester format allows for the robot project to develop at a reasonable pace. The first few sessions devoted to the project are spent assembling components of the robot per the instructions provided with the kits. In this way, students do not feel overwhelmed with the idea of designing a system, but rather become familiar with the components by simply following the instructions. For some students who may have limited experience building anything, these sessions can be used to develop some basic hands-on skills and improving confidence. Later in the semester, teams of students begin to design modifications to the robot to accomplish a specified task. In fall 2005, the task was to pick up objects and deposit them in a designated area. The designs were formulated with solid modeling software, and then built. Figure 2 shows the design concept of one of the student teams, using gates to "sweep" parts into the robot body. CAD models of standard components from the robot kit are available from the GEARS website; students imported these standard parts into their assemblies and mated them with their designed components. Figure 3 shows the as-built robot.

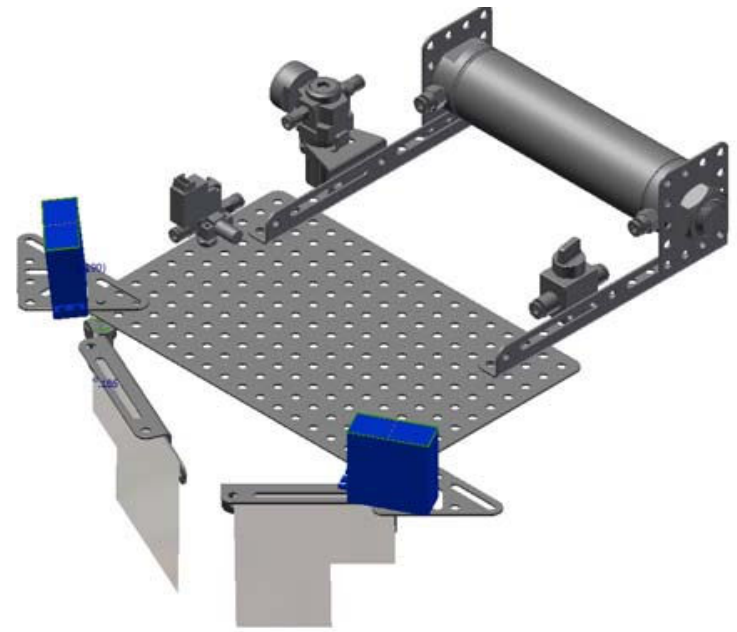

Figure 2

Solid Model of Robot Assembly

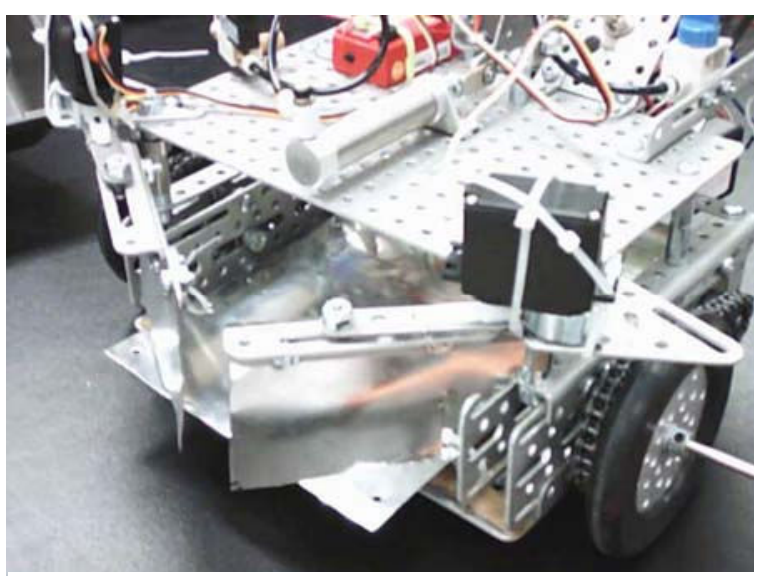

Figure 3

As-Built Robot

\section{Conclusions}

Solid modeling is a tool that students find easy and fun to use, but is also an important tool in real world applications. Expanding the use of solid modeling in education beyond traditional graphics courses has the potential to increase student motivation and confidence, and to serve as the foundation for teaching students valuable project management and design skills early in the engineering curriculum. 


\section{References}

${ }^{1}$ Brannan, K.P. and Wankat, P.C., "Survey of First-Year Programs", ASEE 2005 Annual Conference.

2 "Criteria for Accrediting Engineering Programs; Effective for Evaluations During the 2006-2007 Accreditation Cycle.” ABET, Inc., www.abet.org.

${ }^{3}$ Crockett, R., Koch, M., and Walsh, D., “A Freshman Design Experience Using RPT,” ASEE 2004 Annual Conference.

${ }^{4}$ Dee, K.C. and Livesay, G.A., "First-Year Students Who Leave Engineering: Learning Styles and Self-Reported Perceptions," ASEE 2004 Annual Conference.

${ }^{5}$ Besterfield-Sacre, Atman, and Shuman, "Characteristics of Freshman Engineering Students: Models for Determining Student Attrition in Engineering," Journal of Engineering Education, April 1997.

${ }^{6}$ Sorby, S.A., and Baartmans, B.J., The Development and Assessment of a Course for Enhancing the 3-D Spatial Visualization Skills of First Year Engineering Students," Journal of Engineering Education, July 2000.

${ }^{7}$ Peters, M., Chisholm, P., and Laeng, B., "Spatial Ability, Student Gender, and Academic Performance," Journal of Engineering Education, January 1994.

${ }^{8}$ Sorby, S.A., "A "New and Improved" Course for Developing Spatial Visualization Skills,” ASEE 2001 Annual Conference.

${ }^{9}$ SolidWorks is a registered trademark of the SolidWorks Corporation, 300 Baker Avenue, Concord, MA 01742.

${ }^{10}$ eDrawings is a trademark of the SolidWorks Corporation, 300 Baker Avenue, Concord, MA 01742.

${ }^{11}$ Otto, K. and Wood, K., Product Design: Techniques in Reverse Engineering and New Product Development, Prentice-Hall, 2000.

${ }^{12}$ Musto, J.C., Howard, W.E., and Rather, S., "Using Solid Modeling and Rapid Prototyping in a Mechanical Engineering Outreach Program of High School Students," The International Journal of Mechanical Engineering Education, Vol. 32, Number 4, October 2004.

${ }^{13}$ Musto, J. and Howard, W. E., "The Use of Solid Modeling in Mechanical Engineering Outreach Programs for High School Students," ASEE 2001 Annual Conference.

${ }^{14}$ Summers, D.C.S., and Edmonson, C.P., "Are We Asking Our Students to Do Too Many Projects? It Depends," ASEE 2004 Annual Conference.

${ }^{15}$ www.gearsed.com 